\title{
Primary Malignant Melanoma of Vagina - A Case Report with Review of Literature
}

\author{
Ghosh A, 'Pradhan S, 'Swami R, ${ }^{1}$ KC SR, ${ }^{1}$ Talwar OP' \\ 'Department of Pathology, Manipal College of Medical Sciences, Pokhara, Nepal.
}

\begin{abstract}
Primary vaginal malignant melanoma is a very rare tumor with less than 300 cases reported to date. We describe a case of primary vaginal melanoma and review the literature. A 60 years postmenopausal female patient presented with painless mass coming out of the vagina with occasional bleeding for last 2-3 weeks. On vaginal examination there was a firm polypoidal growth of size $7 \mathrm{~cm}$ attached to the right lateral wall of vagina and coming out of the introitus. Histopathology of the mass showed features of malignant melanoma. Wide local excision was done and adjuvant therapy was given. However patient came back after three months with widespread metastasis and expired 6 months after the initial diagnosis. Vaginal melanoma is a very aggressive tumor and the overall prognosis is very poor despite the treatment modality.
\end{abstract}

Key words: Malignant melanoma, Primary vaginal melanoma, Vaginal malignancy .

\section{INTRODUCTION}

Primary vaginal malignant melanoma is a very rare tumor with less than 300 reported cases world wide. ${ }^{1}$ It accounts for less than $1 \%$ of all melanomas in women, less than $10 \%$ of all melanomas of female genital tract, and less than $3 \%$ of all vaginal malignancies. ${ }^{2,3,4}$ In female genital tract, malignant melanoma is more common in the vulva. In Japanese women, it was seen more frequently in the vagina than in the vulva, which is quite the opposite in cases of United States and Europe. ${ }^{5}$ Malignant melanoma of the vagina mainly occurs in postmenopausal women, with $75 \%$ of patients being over 50 years. $^{3}$ Its clinical behavior is notoriously more aggressive than that of cutaneous and vulvar melanoma with a 5 -year survival rate ranging from $5 \%$ to $25 \%$. $^{2,4,6,7}$ Tumor size is the strongest predictor of survival, whereas tumor thickness is a weak predictor of survival. ${ }^{2}$

\section{CASE REPORT}

A 60 years postmenopausal female presented with a painless mass coming out of vagina with occasional bleeding for last 2-3 weeks. On vaginal examination there was a well defined firm polypoidal growth of size $7 \mathrm{~cm}$ attached to the right lateral wall of vagina and coming out of the introitus. Vulva and cervix were healthy. Biopsy was done and sent for histopathology. Sections showed stratified squamous epithelium with several infiltrating nests of tumor cells while subepithelium showed infiltrating malignant cells arranged in sheets and nesting pattern intimately intermingled with lymphocytes, neutrophils and many congested capillaries. Most of the cells show scant cytoplasm, absence of melanin pigment, reversed nuclearcytoplasmic ratio and smudged chromatin with inconspicuous nucleoli. At many foci cells showed prominent intracytoplasmic

\author{
Correspondence: \\ Dr. Arnab Ghosh \\ Department of pathology \\ Manipal College of Medical Sciences \\ Pokhara, Nepal. \\ Email: drghosharnab@yahoo.com
}


vacuolation which are negative with PAS and mucicarmine. Several of the malignant cells however showed intracytoplasmic melanin pigment positive with Masson Fontana and some of clusters showed cells with scant cytoplasm, vesicular nuclei with coarse chromatin and centrally located macronucleoli. Abnormal mitosis is seen up to 0-1 per high power field (HPF). The malignant cells are seen to infiltrate to the deepest layers of the tissue sample measuring $5 \mathrm{~mm}$ from the surface epithelium. Lymphovascular emboli were not seen. The diagnosis given was malignant melanoma, high risk (Breslow's system). Wide local excision was done with adjuvant radiotherapy and also three cycles chemotherapy with dacarbazine were given. Section of the tumor showed similar picture with tumor thickness of $3 \mathrm{cms}$. However patient came back after three months with recurrence of tumor, widespread metastasis including lymph nodes, liver and lung and pleural effusion. She expired within one week, after six months of initial diagnosis (Figure 1-4).

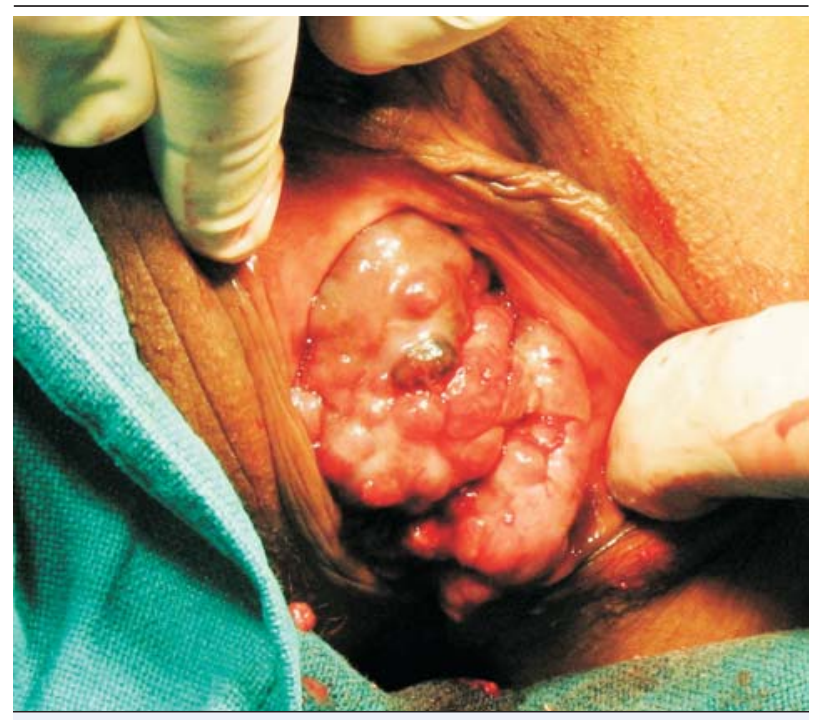

Figure 1. Vaginal tumor mass protruding into the introitus. Vulva is free.

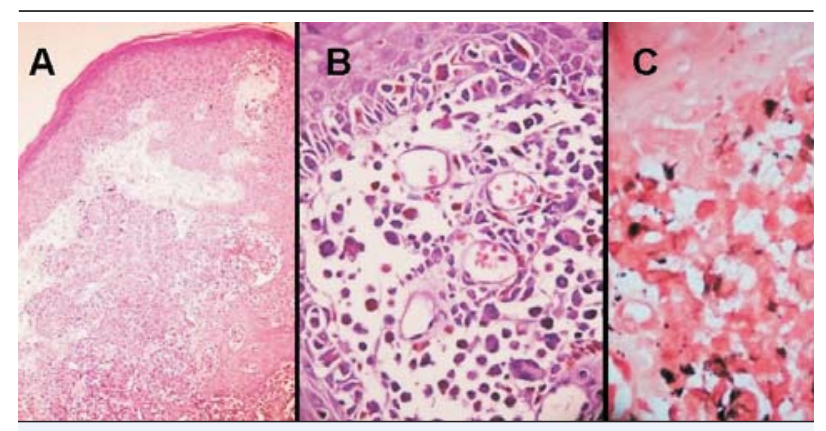

Figure 2. A. Vaginal squamous epithelium with infiltrating tumor in the subepithelium , H\&E, 100x. B. Tumor cells with melanin pigment, H\&E 400x. C. Tumor cells with melanin pigment, Masson Fontana, 1000x

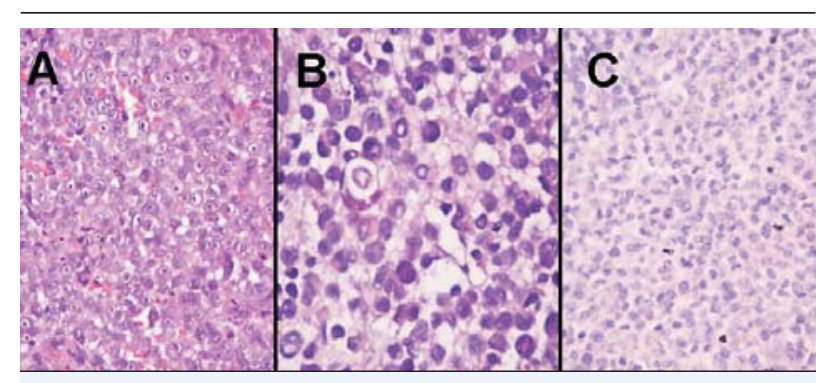

Figure 3. A. Tumor cells showing prominent nucleoli, $H \& E, 400 x$. B. Cells with PAS-negative cytoplasmic vacuolation, PAS, 400x. C. Areas with scant cytoplasm and lack of melanin pigment, H\&E, 100x

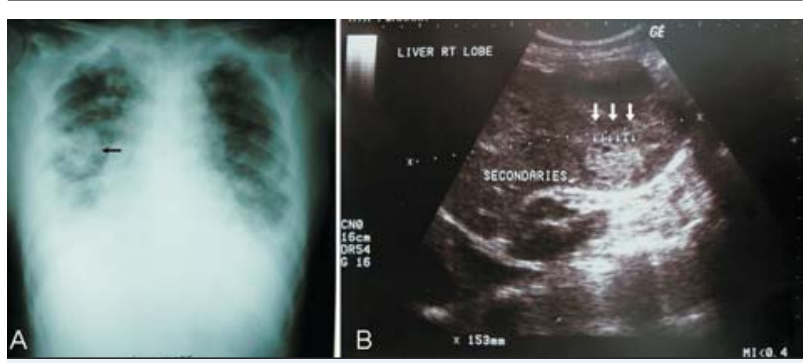

Figure 4. A . Chest $X$ Ray showing metastasis (black arrow ) with effusion B. USG showing secondaries in liver (white arrows)

\section{DISCUSSION}

Primary malignant melanoma of the vagina is a rare entity first reported by Poronas in $1887 .^{8}$ It may occur at any age but is mainly a disease of postmenopausal women with $75 \%$ of patients being 50 and older. ${ }^{6,7,8}$ The most common presenting symptom is vaginal bleeding, followed by vaginal mass. ${ }^{4,6}$ Grossly, the tumor is polypoid to nodular in the majority of cases. ${ }^{6}$ Melanoma is a great mimicker and can present with spectrum of cytological feature like clear cells, spindle cells, signet ring cells and even plasmacytoid type. However usually focus of classical cells with vesicular nucleus, prominent large nuclei and melanin pigment exist. The diagnosis of melanoma can only be made on the presence of these areas otherwise needs to be confirmed by immunohistochemistry. ${ }^{6}$ In the present case, there were variation in the cells with clearing of cytoplasm, small cells and amelanotic undifferentiated cells, however the diagnosis were made on the basis of the presence of classical melanoma cells. The differential diagnosis includes metastasis from other sites, poorly differentiated squamous cell carcinoma, sarcoma, lymphoma and blue nevus. It has a poor prognosis associated with a high rate of recurrences and rare long-term survival. ${ }^{7}$ The prognosis is poor with a five year survival rate ranging from $5-25 \% .^{2}$ It appears to be influenced by tumor size with lesions greater than $3 \mathrm{~cm}$ having a worse 
prognosis. ${ }^{2,6,9}$ Age, mitotic count, stage and location of the lesion do not influence survival. Comments on Clark levels are not possible due to lack of normal anatomical landmarks. ${ }^{6,9}$ In the literature, wide local excision with adjuvant radiotherapy is recommended and radical surgery with adjuvant radiotherapy as secondline therapy. Both procedures show similar five year survival rates. ${ }^{1,7}$ Immunotherapy with interferon-alpha has been tried to minimize metastasis and chemotherapy is used in cases wide spread metastasis. ${ }^{1,10}$ However the prognosis of vaginal melanoma is very poor, despite the treatment modality, because most cases are diagnosed at a late stage. ${ }^{10}$

\section{CONCLUSION}

In conclusion, although rare, melanoma forms one of the differential diagnoses of primary vaginal malignancy and carries a poor prognosis.

\section{REFERENCES}

1. Betschart C, von Orelli S, Mihic D, Fink D. Primary malignant melanoma of the vagina-case report and review of the literature. Gynakol Geburtshilfliche Rundsch 2007;47(1):39-44.

2. Piura B, Rabinovich A, Yanai-Inbar I. Primary malignant melanoma of the vagina: case report and review of literature. Eur J Gynaecol Oncol 2002;23(3):195-8.

3. Levitan Z, Gordon AN, Kaplan AL, Kaufman RH. Primary malignant melanoma of the vagina : report of four cases and review of the literature. Gynecol Oncol 1989;33:85-90.

4. Reid GC, Schmidt RW, Roberts JA, Hopkins MP, Barrett RJ, Morley GW. Primary melanoma of the vagina: a clinicopathologic analysis. Obstet Gynecol 1989;74:190-9.

5. Ikegaya H, Iwasaki T, Matsuda I, Satodate R, Sasou S. Primary amelanotic malignant melanoma of the vagina - a case report. Gan No Rinsho 1987; 33(12):1515-23.

6. Gupta D, Malpica ADeavers MT, Silva EG. Vaginal melanoma: a clinicopathologic and immunohistochemical study of 26 cases. Am J Surg Pathol 2002 Nov; 26(11): 1450-7.

7. Moros ML, Ferrer FP, Mitchell MJ, Romeo JA, Lacruz RL. Primary malignant melanoma of the vagina - poor response to radical surgery and adjuvant therapy. Eur J Obstet Gynecol Reprod Biol 2004 Apr 15;113(2):248-250.

8. Manlucu ED,Dickson H,Mahood L,Nath ME. Case 167 - Bloody Vaginal Discharge, Final Diagnosis - Primary Malignant Melanoma of the Vagina. [Online]. 1998 [cited 1998 Oct];[2 screens]. Available from: URL:http:/ / path.upmc.edu/cases/case167/dx.html

9. Liu LY, Hou YJ, Li JZ. Primary malignant melanoma of the vagina: a report of seven cases. Obstet Gynecol. 1987 Oct;70(4):569-72.

10. Androutsopoulos G, Adonakis G, Ravazoula P, Kourounis G. Primary malignant melanoma of the vagina: a case report. Eur J Gynaecol Oncol 2005;26(6):661-2. 